(c) American Dairy Science Association, 2006.

\title{
Improving Farm Management by Modeling the Contamination of Farm Tank Milk with Butyric Acid Bacteria
}

\author{
M. M. M. Vissers, ${ }^{\star 1}$ F. Driehuis, ${ }^{*}$ M. C. Te Giffel, ${ }^{*}$ P. De Jong, $\dagger$ and J. M. G. Lankveld‡ \\ *Department of Health and Safety, and \\ †Department of Processing, NIZO Food Research, PO Box 20, 6710 BA Ede, The Netherlands \\ $\ddagger$ Wageningen University and Research Centre, PO Box 8129, 6700 EV Wageningen, The Netherlands
}

\section{ABSTRACT}

Control of contamination of farm tank milk (FTM) with the spore-forming butyric acid bacteria (BAB) is important to prevent the late-blowing defect in semihard cheeses. The risk of late blowing can be decreased via control of the contamination level of FTM with BAB. A modeling approach was applied to identify an effective control strategy at the farm level. The simulation model developed was based on a translation of the contamination pathway into a chain of unit operations. Using various simulations, the effects of factors related to feed quality, feed management, cattlehouse hygiene, and milking practices on the contamination level of FTM were evaluated. Contamination level of silage was found to be the most important factor. When silage contains on average less than $3 \log _{10} \mathrm{BAB} / \mathrm{g}$, a basic pretreatment of udder teats before milking ( $75 \%$ removal of attached spores) is sufficient to assure an FTM contamination level below $1 \mathrm{BAB} / \mathrm{mL}$. When silage contains more than $5 \log _{10} \mathrm{BAB} / \mathrm{g}$, it should not be fed, because it then becomes almost impossible to assure an FTM contamination level below $1 \mathrm{BAB} / \mathrm{mL}$. Measures aimed at improving cattlehouse hygiene, the contamination via soil, and the contamination level of other feeds contribute only marginally to the control of the contamination of FTM with BAB. Application of the modeling methodology could be beneficial for the control of the contamination of FTM with other microorganisms such as Bacillus cereus.

Key words: modeling, butyric acid bacteria, farm management

\section{INTRODUCTION}

Spores of butyric acid bacteria are important for the dairy industry with respect to spoilage of semihard cheeses. Clostridium tyrobutyricum specifically is able to convert lactic acid into butyric acid at relatively low

Received May 17, 2005.

Accepted November 1, 2005.

${ }^{1}$ Corresponding author: marc.vissers@nizo.nl
$\mathrm{pH}$. These characteristics and the ability to survive pasteurization enable $C$. tyrobutyricum to grow in semihard cheeses such as Gouda and Emmenthaler, resulting in off-flavors and excessive gas formation (the late-blowing defect). Contamination levels of butyric acid bacteria (BAB) as low as $0.01 \mathrm{cfu} / \mathrm{mL}$ can cause the late-blowing defect in Gouda-type cheeses (Bergere and Hermier, 1970; Klijn et al., 1995).

To prevent late blowing, cheese manufacturers have 3 options: 1) encourage farmers to reduce the contamination level in farm tank milk (FTM), 2) add nitrate and lysozyme to cheese milk to prevent growth of $\mathrm{BAB}$, and 3) remove 95 to $99 \%$ of the spores during cheese production via bactofugation (Stadhouders, 1990; Waes et al., 1990). In the Netherlands, farmers are encouraged to control FTM contamination with $\mathrm{BAB}$ via a penalty system. In this system, farmers receive a deduction on milk price when the contamination level of $\mathrm{BAB}$ spores in FTM at the point of delivery results in $2 \mathrm{BAB}-$ positive samples of $0.1 \mathrm{~mL}$ FTM (Berg et al., 1989). After introduction of this penalty system, the fraction of penalized samples declined from approximately $7 \%$ in the 1980 s to $2 \%$ in the mid-1990s. Since then, the fraction of penalized samples has remained more or less constant (MCS, 2001).

Butyric acid bacteria spores present in FTM originate from the farm environment. The spores are naturally present in soil but during daily practice, silage and other feeds such as brewer's grain and hay also act as sources of contamination. Butyric acid bacteria are transmitted from these sources to the FTM via a number of steps. Feces are considered the main carrier in the contamination pathway (Bergere et al., 1968). Along the contamination pathway, microbial transmission, growth, and inactivation take place. A farmer can reduce the contamination level of FTM via 1) minimization of the introduction of $\mathrm{BAB}$ to the farm environment, 2) minimization of transmission, 3) minimization of growth, and 4) maximization of inactivation. However, a farmer has to take into account that the achieved FTM contamination level also depends on factors the farmer cannot control, such as the contamination level of soil. 
Numerous studies have been performed to identify measures to control the contamination of FTM with BAB (Bergere et al., 1968; Stadhouders and Jørgensen, 1990). Identified measures relate to feed quality, cattlehouse hygiene, and milking practices. The recommendation is to take various measures in all steps of the contamination pathway. However, practice shows that farmers are not able to take measures in all steps and tend to focus on specific steps, do not agree on which measures are most efficient, and interpret good hygiene guidelines differently. Consequently, high concentrations of BAB in FTM still occur. The Dutch dairy industry wants to ensure a contamination level in FTM of less than $1 \mathrm{BAB}$ spore/mL in all cases. To achieve this, farmers need practical definitions of control measures and quantitative insight into the effectiveness of these measures.

Food safety risk assessment (Cassin et al., 1998) and industrial processing (De Jong et al., 2002) frequently apply mathematical modeling to quantitatively identify control strategies. This paper is an attempt to apply a similar modeling approach to the contamination of FTM with $\mathrm{BAB}$. The objective was to quantitatively identify an effective control strategy in practical and measurable terms.

\section{MATERIALS AND METHODS}

\section{Model Development}

The Contamination Pathway in Terms of Unit Operations. A contamination pathway can be seen as a process flow in industrial processing. A process-flow diagram starts with raw materials and consists of the successive unit operations that these materials undergo for the production of the end product. Examples of unit operations are mixing, concentration, and storage. Because of its similarity with a process-flow diagram, the contamination pathway of $\mathrm{BAB}$ can also be translated into a chain of unit operations.

In this translation, the 3 sources of contamination (soil, silage, and other feeds) correspond to raw materials. Silage comprises grass and corn silage; other feeds comprise all possible feeds fed to the cows other than silage, such as concentrates, brewer's grain, and hay. Silage and the other feeds are mixed (unit operation 1) and placed in front of the cows. The period between the mixing of the feed ration and consumption of the ration by a cow is a storage (unit operation 2) period. During storage, growth of BAB can occur when conditions such as temperature, $\mathrm{pH}$, and availability of nutrients are favorable. In the digestive tract of the cows, the larger part of the feed is consumed but BAB spores survive and are excreted in the feces. This means that spores are concentrated (unit operation 3 ) during transmission from feed to feces. During excretion and lying down, contaminated feces and soil attach to the surface of the udder teats. In this paper, the mixture of attached soil and feces is referred to as dirt. The contamination of teats with dirt then relates to 2 unit operations, mixing (unit operation 4) of soil and feces into dirt and crosscontamination (unit operation 5) between dirt and teats. Before milking, a farmer can pretreat the teats to remove (unit operation 6) spores. The remaining spores are diluted (unit operation 7) in the raw milk during milking. Via the milkline, contaminated milk is transferred to the farm tank, where the milk of all cows from a number of milkings is mixed (unit operation 8) before transportation to the dairy plant.

The Simulation Model. For model development, translation of the contamination pathway into a chain of unit operations has the advantage that predictive microbial models are available to describe the effect of unit operations on microbial behavior. All variables in these predictive models can be related to processing parameters or product characteristics. This makes it possible to evaluate different control strategies in practical and measurable terms.

In the Netherlands, the FTM transported to the dairy plant is a collection of milk yields of individual cows from 6 successive milkings over $3 \mathrm{~d}$. Therefore, the model developed simulates the FTM contamination level after 6 milkings. Predictive microbial models used to calculate the FTM contamination level $\left(C_{F T M}\right)$ are listed in Table 1. The simulation model first calculates the number of BAB transmitted to the FTM of each cow during each milking ( $N_{i, k}$; unit operations 1 to 6$)$. Then, the FTM contamination level after 6 milkings $\left(C_{F T M}\right)$ is calculated based on $N_{i, k}$ and the milk yield $\left(V_{\text {milk }, i, k}\right)$ of the different cows during the different milkings.

Microbial growth in the feed ration is simulated using the Baranyi growth model (Baranyi and Roberts, 1994). The Baranyi model was applied because it accounts for a maximum attainable contamination level $(C \propto)$, which could be relevant for the growth in the feed ration. With the gamma concept of Zwietering et al. (1996), the growth rate $\mu$ was estimated. The gamma concept was chosen because the effects of temperature and $\mathrm{pH}$ can be separated, and parameter values $\left(T_{\min }, T_{\text {opt }}\right.$, $p H_{\min }, p H_{o p t}, p H_{\max }$, and $\left.\mu_{\max }\right)$ are available in the literature. Table 2 shows the values of these parameters for C. tyrobutyricum.

Cattlehouse Hygiene. Cattlehouse hygiene is considered an important factor for the contamination of FTM with BAB (Stadhouders and Jørgensen, 1990). To account for differences between cows and to have a practical measure of cattlehouse hygiene, the herd was divided into 3 groups. The groups were 1) slightly con- 
Table 1. Predictive microbial models used to calculate the number of butyric acid bacteria transferred to farm tank milk (FTM) by each cow of a herd during each separate milking ( $N_{i, k}$ in cfu) and the resulting FTM contamination level $\left(C_{F T M}\right.$ in $\left.\mathrm{cfu} / \mathrm{mL}\right)$

Unit operation Equation

1. Mixing of silage and other feedstuffs resulting in the contaminated feed ration ${ }^{1}$

$$
\begin{aligned}
& C_{\text {ration }}(0)=F_{\text {silage }} \times C_{\text {silage }}+\left(1-F_{\text {silage }}\right) \times C_{\text {otherfeed }} \\
& \ln \left[C_{\text {ration }}(t)\right]=\ln \left[C_{\text {ration }}(0)\right]+\mu \times A_{N}(t) \\
& -\ln \left(1+\frac{e^{\mu \cdot A_{n}(t)} \times t}{e^{\ln \left(C_{\left.\propto^{\prime} C_{\text {ration }}(0)\right)}\right.}}\right) \\
& A_{n}(t)=t+\frac{1}{\mu} \ln \left(\frac{e^{-\mu \cdot t}+q_{0}}{1+q_{0}}\right) \\
& q_{0}=\frac{1}{e^{\lambda \cdot \mu}-1} \\
& \mu=\gamma(T) \times \gamma(p H) \times \mu_{o p t} \\
& \gamma(T)=\left(\frac{T_{\text {ration }}-T_{\min }}{T_{\text {opt }}-T_{\min }}\right)^{2}, \\
& \gamma(p H)=\left[\frac{\left(p H_{\text {ration }}-p H_{\min }\right) \times\left(p H_{\max }-p H_{\text {ration }}\right)}{\left(p H_{\text {opt }}-p H_{\min }\right) \times\left(p H_{\max }-p H_{\text {opt }}\right)}\right] \\
& C_{\text {feces }}=\left(\frac{1}{1-F_{\text {digested }}}\right) \times C_{\text {ration }}(t)
\end{aligned}
$$

3. Relation between concentration in the feed ration and in the feces ${ }^{3}$

4. Mixing of soil and feces resulting in contaminated dirt ${ }^{1}$

5. Cross contamination of udder teats ${ }^{4}$

6. Removal during pretreatment ${ }^{5}$

\footnotetext{
${ }^{1}$ The contamination level of a carrier $\mathrm{X}$ after mixing $\left(C_{\text {ration( }(0)}, C_{\text {dirt }}\right)$ was calculated as a function of the contamination level of the preceding carriers $\left(C_{\text {silage }}, C_{\text {otherfeed }}, C_{\text {soil }}, C_{\text {feces }}\right)$ and the fraction of these preceding carriers $\left(F_{\text {silage }}, F_{\text {soil }}\right)$ in carrier X. All contamination levels (noted with $\mathrm{C}^{*}$ ) are in $\mathrm{cfu} / \mathrm{g}$ and all fractions (noted with $\mathrm{F}^{*}$ ) in \%.

${ }^{2}$ The Baranyi growth model (Baranyi and Roberts, 1994) was applied to calculate the contamination level of the feed ration after growth $\left(C_{\text {ration }}(t)\right)$. Lag time $\lambda\left(\right.$ in $\left.^{-1}\right)$ equals $1 / \mu$ and $t(\mathrm{~h})$ is the time available for growth. The gamma-concept with $\gamma$-factors for temperature and $\mathrm{pH}$ was used to estimate the growth rate $\mu$ in $\mathrm{h}^{-1}$ (Zwietering et al., 1996).

${ }^{3} F_{\text {digested }}(\%)$ refers to the fraction of the feed ration digested.

${ }^{4} M_{\text {dirt }}$ (g) refers to the mass of dirt attached to the udder teats that will dilute in the milk without pretreatment. $N^{*}$ (cfu) refers, in all cases, to the number of microbial cells.

${ }^{5}$ This equation is based on Chen et al. (2001). $P T_{\text {efficiency }}(\%)$ relates to the percentage of spores removed by the pretreatment method applied.

${ }^{6}$ Subscript i refers to the different cows in the herd, subscript $k$ to the different milkings; $V_{i, k}$ is the milk yield for cow $i$ during milking $k$ in L.
}

taminated cows with no visible dirt attached to the teats, 2) moderately contaminated cows with visible dirt attached to the teats, and 3) highly contaminated cows with excessive amounts on the teats. The proportions of slightly and moderately contaminated cows are an indicator of cattlehouse hygiene. Highly contami- nated cows prefer to lie down on dirty patches. This preference is generally a cow characteristic and therefore the proportion of highly contaminated cows is not related to cattlehouse hygiene per se. In the simulation model, each cow group corresponds to a different amount of dirt attached to the teats. In the calculation 
Table 2. Growth characteristics of butyric acid bacteria

\begin{tabular}{llc}
\hline Parameter name & Abbreviation & Value \\
\hline Minimum growth temperature $\left({ }^{\circ} \mathrm{C}\right)$ & $T_{\min }{ }^{2}$ & 9 \\
Optimum growth temperature $\left({ }^{\circ} \mathrm{C}\right)$ & $T_{o p t}$ & 37 \\
Minimum pH required for growth & $p H_{\min }$ & 4.4 \\
Optimum pH for growth & $p H_{o p t}$ & 5.6 \\
Maximum pH allowed for growth & $p H_{\max }$ & 6.8 \\
Growth rate under optimal conditions $\left(\mathrm{h}^{-1}\right)$ & $\mu_{\text {opt }}$ & 0.12 \\
\hline
\end{tabular}

${ }^{1}$ Data from Bergere and Hermier (1970) and Thylin et al. (1995).

${ }^{2} T_{\min }$ is the minimum temperature at which growth is reported minus $1^{\circ} \mathrm{C}$ (Zwietering et al., 1996).

procedure, each cow was first assigned to a cow group based on the proportions of highly and moderately contaminated cows; then, the number of BAB transferred to the FTM via the teats of this cow was calculated $\left(N_{i, k}\right)$.

Model Variables. The model distinguishes between controllable and uncontrollable variables. A variable was considered controllable when a farmer can directly influence the value via management or can measure the variable easily, and respond to the results of this measurement. Worst, optimal, and average values currently applicable to common farm practices in the Netherlands were retrieved from published data and opinions from experts in the Dutch dairy industry. Table 3 shows these values. In this respect, worst and optimal refer to the direction of the effect of the variable on the FTM contamination level (worst settings result in higher contamination levels; optimal settings result in lower contamination levels).

All other variables selected for the final simulation model were considered uncontrollable. All uncontrollable variables were modeled with statistical distributions. Distributions were applied because extreme values of uncontrollable variables affect the occurrence of extremely high values of the FTM contamination level.
Because the dairy industry wants to assure a contamination level below $1 \mathrm{cfu} / \mathrm{mL}$, these extreme values are particularly important. The selected uncontrollable variables and their distributions are listed in Table 4. The distributions were also retrieved from published data and expert opinions.

All variable values and distributions in Tables 3 and 4 refer to cows housed in the cattlehouse (winter period); different values and distributions would apply for cows in pasture (summer period).

\section{Model Simulations}

The simulation model was programmed in Microsoft Excel (2002 version, Microsoft Corp., Redmond, WA). The Excel plug-in @Risk (2002 version, Palisade Corp., Newfield, NY) was used to implement the distributions of the uncontrollable variables. Simulations were performed using Latin hypercube sampling. Each simulation comprised 2,500 iterations.

The following assumptions apply to the programmed model and performed simulations:

1) The composition of the feed ration is constant during a period of 6 milkings. In practice, feed rations do not change daily, so this assumption does not conflict with practice. A constant feed ration implies that the residence time of the $\mathrm{BAB}$ spores in the gastrointestinal tract can be neglected.

2) The lag time for growth in the feed ration is assumed to equal $1 / \mu$, an estimate frequently applied in food safety risk assessment (Zwietering, et al., 1996).

3) The maximum attainable contamination level in the feed ration $\left(C_{\infty}\right)$ was assumed to be $8 \log _{10}$ $\mathrm{BAB} / \mathrm{g}$.

Table 3. Worst, average, and optimal values of controllable variables as encountered in the Netherlands ${ }^{1}$

\begin{tabular}{|c|c|c|c|c|c|}
\hline Variable & Abbreviation & Worst & Average & Optimal & Reference \\
\hline Herd size & $N$-herd & 30 & 65 & 125 & Expert opinion \\
\hline Mean contamination level in silage $(\log 10 \mathrm{cfu} / \mathrm{g})$ & $C$-silage & 7 & 4 & 2 & Pahlow et al. (2003) \\
\hline Mean contamination in other feeds $(\log 10 \mathrm{cfu} / \mathrm{g})$ & $C$-other feed & 3 & 1 & 0 & Dasgupta and Hull (1989) \\
\hline $\mathrm{pH}$ of feed ration & pH-ration & 5.6 & 5.0 & $<4.4$ & $\begin{array}{l}\text { Unpublished data from Blgg } \\
\text { (Oosterbeek, The Netherlands) }\end{array}$ \\
\hline Temperature of feed ration $\left({ }^{\circ} \mathrm{C}\right)$ & Temp-ration & 37 & 20 & 10 & Expert opinion, Dutch dairy industry \\
\hline Time between 2 feed ration refreshments (h) & Time-ration & 144 & 24 & 6 & Expert opinion, Dutch dairy industry \\
\hline Proportion of highly contaminated cows (\%) & $H C$-cows & 5.0 & 2.5 & 0.0 & Expert opinion, Dutch dairy industry \\
\hline Pretreatment strategy ${ }^{2}$ & PT-strategy & 0 & 2 & 3 & Expert opinion, Dutch dairy industry \\
\hline Mean pretreatment efficiency (\%) & PT-efficiency & 30 & 75 & 90 & $\begin{array}{l}\text { Stadhouders and Jørgensen (1990); } \\
\text { expert opinion }\end{array}$ \\
\hline
\end{tabular}

${ }^{1}$ The terms worst and optimal relate to the effect on the contamination level of farm tank milk.

${ }^{2}$ Pretreatment strategies: $0=$ no cows; $1=$ highly contaminated cows; $2=$ highly + moderately contaminated cows; $3=$ all cows. 


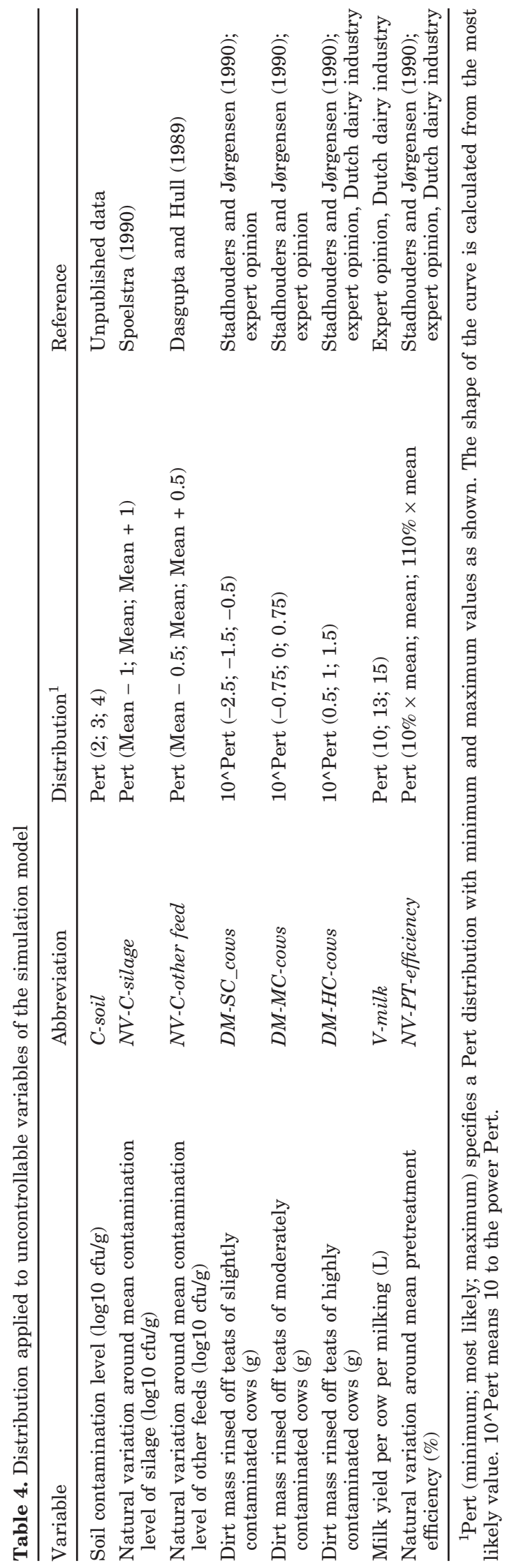

4) The same pretreatment method is applied to cows with the same amount of dirt attached to the udder teats for all milkings.

5) All BAB present on the udder teats surface before milking are rinsed off and diluted in the raw milk. This assumption was necessary because data are available only about the amount of dirt transferred to milk.

6) Dutch farmers generally milk twice a day and milkings were assumed to take place at regular intervals of $12 \mathrm{~h}$.

\section{RESULTS}

\section{Model Validation}

Validation of the developed model was difficult because only data concerning contamination levels of different carriers were available, without information about the related management conditions. Therefore, expert opinion was used together with experimental data to validate the model. Predicted contamination levels corresponded with experimental data of Bergere et al. (1968) and Kalzendorf (1996).

To validate observed trends, the simulation results were discussed with experts from the field. In qualitative terms, the observed trends corresponded with the experience of the experts and did not conflict with practice. The quantitative validation of the predicted contamination levels and qualitative validation of observed trends showed the reliability of the developed simulation model.

\section{Identification of Important Controllable Variables}

To identify the most important controllable variables, the mean FTM contamination level was first simulated with the value of all controllable variables fixed on their average values (Table 3). Then, for each controllable variable, 2 additional simulations were performed. In the first simulation, the mean FTM contamination level was calculated with the value of the specific controllable variable fixed on its worst value, and the other controllable variables fixed on their average value. In the second simulation, the same procedure was repeated but with the value of the controllable variable fixed on its optimal value.

Figure 1 shows the calculated mean FTM contaminations levels for all controllable variables. Controllable variables are represented in order of decreasing contamination level for the worst-case scenario. For the effect of the variation of the average silage contamination level, a separate y-scale was used because the impact of this controllable factor exceeded, by far, the impact of the other factors. 

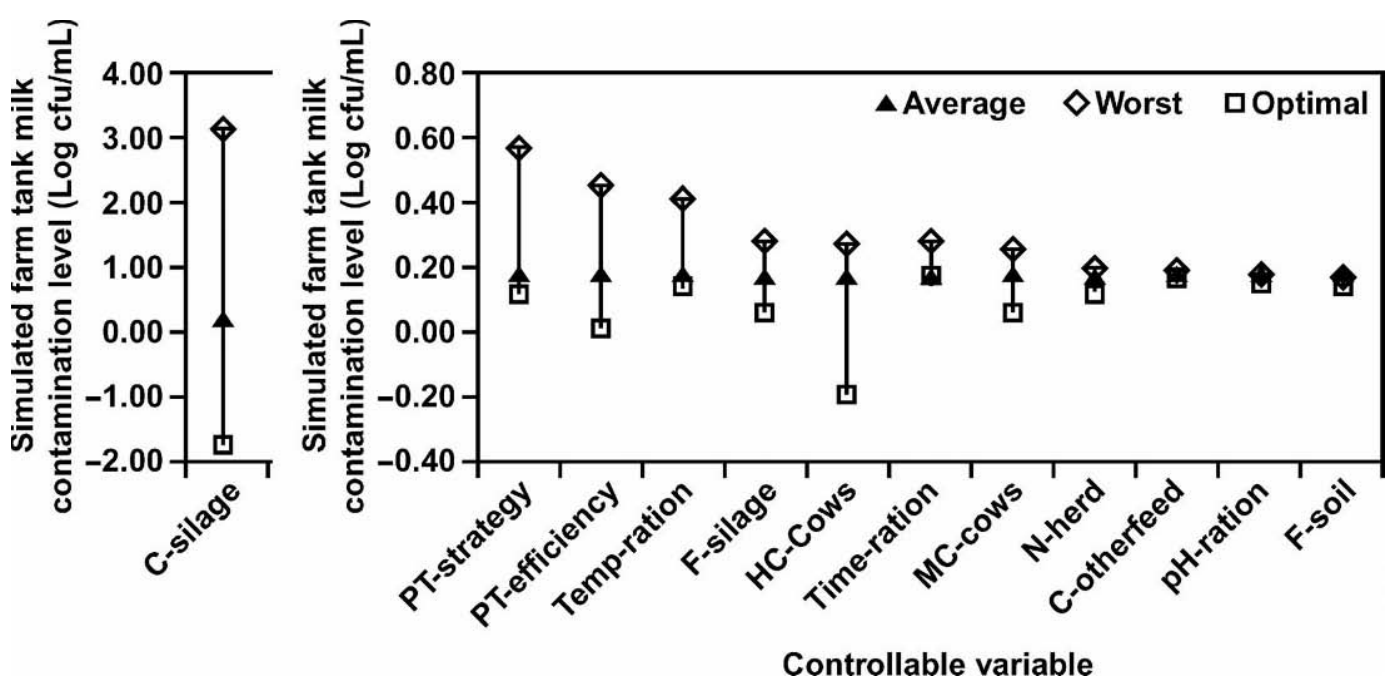

Figure 1. Simulated impact of the different controllable variables on the mean bulk tank milk contamination level; the controllable variables (x-axis) are defined in Table 3. $\boldsymbol{\Delta}=$ All controllable variables fixed on average value; $\diamond=$ specific variable fixed on worst value and all other variables on average value; $\square=$ specific variable fixed on optimal value and all other variables on average value. Average, worst, and optimal values are given in Table 3. A separate y-axis was used for the average silage contamination level because the impact of this controllable factor exceeded, by far, the impact of the other factors.

A large difference between calculated mean contamination levels at worst and optimal settings implies that the specific variable has a large impact on the contamination level. This implies that the average silage contamination level (C-silage) is by far the most important determinant for the achieved FTM contamination level. Other important factors are the pretreatment strategy (PT-strategy), efficiency of the applied pretreatment method (PT-efficiency) and the proportion of highly contaminated cows (HC-cows). Variables directly related to farm hygiene (MC-cows, F-soil) have only a marginal impact, as does the contamination level of the other feeds. Variables are defined in Table 3.

For the pretreatment strategy, the calculated FTM contamination level for the average and optimal scenarios are almost equal. This implies that little can be gained from pretreatment of slightly contaminated cows. Compared with the average situation, it is most effective to remove highly contaminated cows from the herd and to apply a more severe pretreatment method $(\sim 90 \%$ removal).

\section{Identification of Important Uncontrollable Variables}

To determine the most important uncontrollable variables, the values of all controllable variables were fixed at their average value and the values of all uncontrollable variables, except the one under investigation, were fixed on their most likely value. The mean, and 5 and 95\% values of the FTM contamination level were then calculated. For comparison, an additional simulation was performed with all uncontrollable variables varying according to their distribution.

Figure 2 shows the results, with error bars representing the difference between the mean and percentile values. The variables are presented in order of decreasing difference between the 5 and $95 \%$ percentile values. The larger this difference, the more important the specific uncontrollable variable is for the achieved FTM contamination level. Figure 2 shows the natural variation of the silage contamination level (NV-C-Silage) to be the most important uncontrollable variable.

\section{Relationship Between Silage and FTM Contamination Level}

Silage was shown to be the most important factor. To establish the relation between silage and FTM contamination level, extra simulations were performed. In these calculations, the average silage contamination level was fixed at $2,3,4,5,6$, and $7 \log _{10} \mathrm{BAB} / \mathrm{g}$. For each of these silage contamination levels, 3 simulations were performed: 1 with all controllable variable values fixed at their worst value, 1 with all these variable values fixed at their average value, and 1 with all these variable values fixed at their optimal value.

The results were plotted in a graph with the average silage contamination on the x-axis and the FTM contamination on the y-axis; error bars represent the 5 and $95 \%$ percentile values (Figure 3 ). This graph also shows the desired FTM contamination level (1 BAB/ $\mathrm{mL}$ ). The $95 \%$ percentile value is important because 


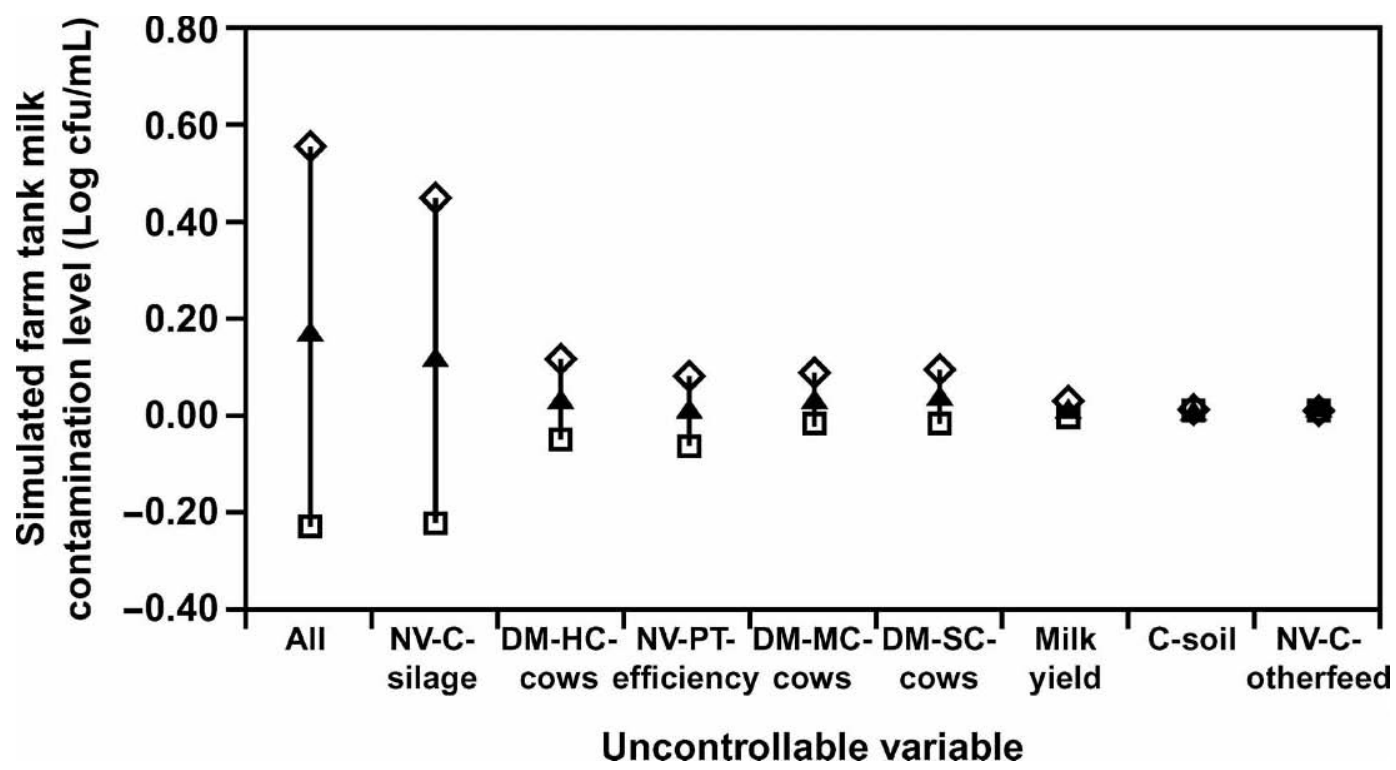

Figure 2. Simulated impact of uncontrollable variables on the variation of bulk tank milk contamination with average values for the controllable variables; uncontrollable variables (x-axis) are defined in Table $4 . \boldsymbol{\Delta}=$ Mean of the bulk tank milk contamination level; $\diamond=$ $95 \%$ percentile value of the simulated farm tank milk contamination level; $\square=5 \%$ percentile value of the simulated farm tank milk contamination level.

the industry wants to assure that FTM contamination is below the desired level at all times. Figure 3 shows that feeding silage with an average contamination level above $5 \log _{10} \mathrm{BAB} / \mathrm{g}$ should be avoided. Average man- agement is sufficient when the mean silage contamination is $3 \log _{10} \mathrm{BAB} / \mathrm{g}$ or lower. Between 3 and $5 \log _{10}$ $\mathrm{BAB} / \mathrm{g}$, additional measures compared with average management are needed; for example, removal of highly

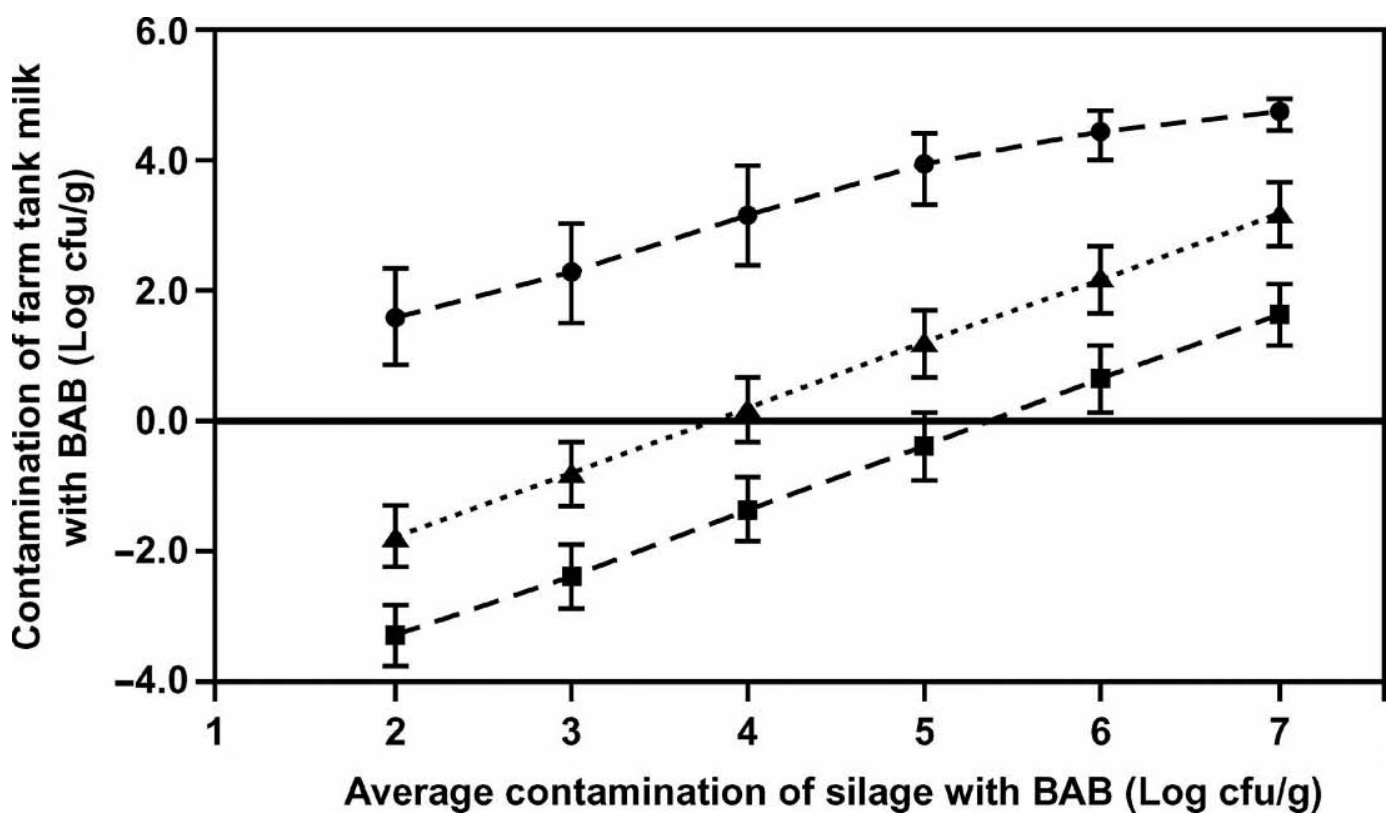

Figure 3. Simulated relationship between the simulated contamination level of farm tank milk with butyric acid bacteria (BAB) and average contamination level of silage. $\bullet=$ All controllable variables fixed at the worst value; $\boldsymbol{\Delta}=$ all controllable variables fixed at the average value; = all controllable variables fixed at the optimal value. Error bars indicate $90 \%$ confidence interval. Average, worst, and optimal values are given in Table 3 . 
contaminated cows or another pretreatment method (see Figure 1).

\section{DISCUSSION}

In this paper, an approach to model the microbial contamination of FTM was applied to the contamination of raw milk with $\mathrm{BAB}$ spores. In this approach, the complex interactions between microorganisms, farm management, and uncontrollable factors are simplified in a mathematical model based on the contamination pathway. The objective was to illustrate the usefulness of the approach and to identify an effective strategy to control the contamination of FTM with BAB.

For a number of variables in the developed model, expert opinion was needed to obtain variable values. Inclusion of expert opinion often increases uncertainty of model predictions. Figure 1 and 2 show that, although large differences for worst and optimal values were applied, only pretreatment strategy and fraction of highly contaminated cows had moderate effects on the predicted FTM contamination level. However, the impact of these 2 variables ( $0.5 \log 10$ difference between highest and lowest value) is much less than the impact of the silage concentration $(\sim 5 \log 10$ difference between highest and lowest value).

Empirical results of Bergere et al. (1968) showed that feeding silage could result in increased contamination of FTM with BAB. They concluded that feeding high quality silage is most important in controlling the contamination level, but that measures at other steps in the contamination pathway are also necessary. Dasgupta and Hull (1989) confirmed the importance of the microbial quality silage experimentally. Our simulation results correspond with these findings; the added value of the simulation model is the quantification of the importance of silage quality compared with other relevant factors.

The simulation confirmed that the first objective of a farmer should be to control the contamination level of the silage. Additional control measures are ineffective when the silage contains more than $5 \log _{10} \mathrm{BAB} / \mathrm{g}$ on average. Dry matter content and $\mathrm{pH}$ of the silage during storage have been identified as important factors for the control of contamination of silage with $\mathrm{BAB}$ (Pahlow et al., 2003). Grass silage with high DM can be achieved via wilting of the grass before ensiling (Pauly et al., 1999). A rapid decrease of the $\mathrm{pH}$ can be achieved via addition of formic acid early in the fermentation process (Beaudouin, 1985).

Figure 2 indicates the importance of natural variation of the silage contamination level to the final FTM contamination level. Variation of the silage contamination level is related to the heterogeneous nature of si- lage (Spoelstra, 1990; Pauly, 1999). Harvesting and ensiling practices influence the heterogeneity of the silage and therefore offer a possibility to further control the contamination of the FTM with BAB. In practice, other risk factors mentioned with respect to high levels of $\mathrm{BAB}$ in silage are the initial contamination of silage with soil and the deterioration of silage during the feedout phase. Currently, further research is being performed to identify which of these factors $(\mathrm{pH}, \mathrm{DM}$, heterogeneity, initial contamination, and deterioration) impose the highest risk for the contamination of silage fed, and which factors or combinations of factors are the most practical indicators for the silage contamination level.

Bergere et al. (1968) and Stadhouders and Jørgensen (1990) emphasized the importance of hygienic milking practice for the control of the FTM contamination. Hygienic milking practice relates to the contamination of teats with dirt and the removal of the dirt during pretreatment. In this respect, cows should be prevented from lying down on dirty patches (this results in highly contaminated teats before milking); and a pretreatment method with an average efficiency of at least $75 \%$ should be applied. Moderately contaminated cows (a small amount of visible dirt) have far less impact on the contamination level of FTM. Herlin and Christiansson (1993) found no relationship between the housing system and the contamination of FTM with anaerobic spores. It can therefore be expected that the proportions of heavily and moderately contaminated cows are independent of the housing system.

Contrary to common belief in practice, soil and feeds other than silage are unimportant sources of BAB. The maximum contamination levels in these sources ( 3 and $4 \log _{10} \mathrm{BAB} / \mathrm{g}$, respectively) are generally negligible compared with the levels in silage (up to $7 \log _{10} \mathrm{BAB} /$ g). Even when only highly contaminated feeds are fed in the absence of silage feeding, average management would be sufficient to achieve the desired FTM quality.

Using data presented in Figures 1 and 3, a general strategy to control the contamination of the FTM below $1 \mathrm{BAB} / \mathrm{mL}$ can be defined. When the average contamination level of silage is below $3 \log _{10} \mathrm{BAB} / \mathrm{g}$, it is sufficient to pretreat the udder teats using a method with an average efficiency of $75 \%$. At average silage contamination levels between 3 and $5 \log _{10} \mathrm{BAB} / \mathrm{g}$ additional measures are necessary. The most efficient additional measures are removing highly contaminated cows from the herd and improving the efficiency of the applied pretreatment method, although Stadhouders and Jørgensen, (1990) consider the most efficient pretreatment method too time-consuming. Silage with more than $10^{5} \mathrm{BAB} / \mathrm{g}$ on average should not be fed, because at these contamination levels even optimal control of 
all other factors will not be sufficient to assure a contamination level below $1 \mathrm{BAB} / \mathrm{mL}$.

\section{CONCLUSIONS}

A mathematical model based on the contamination pathway was shown to be a useful tool for the identification of a strategy to control FTM contamination below $1 \mathrm{BAB} / \mathrm{mL}$. The interpretability of the model variables will facilitate the implementation of the research results into practice. The contamination level of silage was shown to be the most important factor and silage containing on average more than $5 \log _{10} \mathrm{BAB} / \mathrm{g}$ should not be fed to milked cows. Further research is needed to identify the factors that impose the highest risk of an insufficient microbial quality of the silage. Other identified control measures are application of an udder pretreatment method with an efficiency of $75 \%$ or higher and removal from the herd of cows with a preference for lying down on dirty patches.

There are other spore-forming microorganisms, such as Bacillus cereus, that impose problems for the dairy industry besides BAB (Te Giffel et al., 1995). When the contamination pathways for these microorganisms are known, the described approach would be beneficial for decreasing the contamination level of FTM with these microorganisms.

\section{REFERENCES}

Baranyi, J., and T. A. Roberts. 1994. A dynamic approach to predicting bacterial growth in food. Int. J. Food Microbiol. 23:277-294.

Beaudouin, P. 1985. The Finnish solution to butyric acid bacteria. Prod. Laitiere Moderne 139:70-75.

Berg, G. v. d., C. B. G. Daamen, and J. Stadhouders. 1989. Bactofugation of cheese milk. North Eur. Food Dairy J. 55:63-68.

Bergere, J. L., P. Gouet, J. Hermier, and G. Mocquot. 1968. Les Clostridium du groupe butyrique dans les produit laitiers. Ann. Inst. Pasteur 19:41-54.

Bergere, J. L., and J. Hermier. 1970. Spore properties of Clostridia occurring in cheese. J. Appl. Bacteriol. 33:167-179.

Cassin, M., A. Lammerding, E. Todd, W. Ross, and R. McColl. 1998. Quantitative risk assessment for Escherichia coli O157:H7 in ground beef hamburgers. Int. J. Food Microbiol. 41:21-44.

Chen, Y., K. M. Jackson, F. P. Chea, and D. W. Schaffner. 2001. Quantification and variability analysis of bacterial cross-contamination rates in common food service tasks. J. Food Prot. 64:72-80.
Dasgupta, A. P., and R. R. Hull. 1989. Late blowing of Swiss cheese incidence of Clostridium tyrobutyricum in manufacturing milk. Aust. J. Dairy Technol. 44:82-87.

De Jong, P., M. Verschueren, M. M. M. Vissers, J. Straatsma, and F. Smit. 2002. Hybrid modelling for development and optimisation of food production chains including costs and food quality. Pages 13-17 in Proc. 2nd Int. Conf. Simulation in Food and Bio Ind. (Foodsim 2002). SCS Europe, Ghent, Belgium.

Herlin, A. H., and A. Christiansson. 1993. Cheese-blowing anaerobic spores in bulk milk from loose-housed and tied dairy cows. Milchwissenschaft 48:686-690.

Kalzendorf, C. 1996. Durchführung von Massnahmen zur Verbesserung der Rohmilchqualitat durch Reduzierung des ClostridienSporengehaltes. Landesverenigung der Milchwirtschaft Niedersachsen e. V, Oldenburg, Germany.

Klijn, N., F. F. J. Nieuwenhof, J. D. Hoolwerf, C. B. v. d. Waals, and A. H. Weerkamp. 1995. Identification of Clostridium tyrobutyricum as the causative agent of late blowing in cheese by speciesspecific PCR amplification. Appl. Environ. Microbiol. 61:29192924.

MCS. 2001. Annual Report 2001. Netherlands Milk Control Station (MCS), Zuthpen, The Netherlands.

Pahlow, G., R. E. Muck, F. Driehuis, S. J. W. H. Oude-Elferink, and S. F. Spoelstra. 2003. Microbiology of ensiling. Pages 31-93 in Silage Science and Technology. D. R. Buxton, R. E. Muck, and J. H. Harrison, Ed. Soil Sci. Soc. Am., Madison, WI.

Pauly, T. M. 1999. Effect of wilting, chopping and application of growth factors on homogeneity and quality of grass silage. In Heterogeneity and Hygienic Quality of Grass Silage. Doctoral Thesis, Univ. Agric. Sci., Uppsala, Sweden.

Pauly, T. M., I. B. Hansson, and W. A. Tham. 1999. The effect of mechanical forage treatments on the growth of Clostridium tyrobutyricum and Listeria monocytogenes in grass silage. Anim. Feed Sci. Technol. 78:127-139.

Spoelstra, S. F. 1990. Comparison of the content of clostridial spores in wilted grass silage ensiled in either laboratory, pilot-scale or farm silos. Neth. J. Agric. Sci. 38:423-434.

Stadhouders, J. 1990. Prevention of butyric acid fermentation by the use of nitrate. Bull. Int. Dairy Fed. 251:40-46.

Stadhouders, J., and K. Jørgensen. 1990. Prevention of the contamination of raw milk by a hygienic milk production. Bull. Int. Dairy Fed. 251:32-36.

Te Giffel, M. C., R. R. Beumer, B. A. Slaghuis, and F. M. Rombouts. 1995. Occurence and characterizaiton of (psychrotrophic) Bacillus cereus on farms in the Neth. Milk Dairy J. 49:125-138.

Thylin, I., P. Schuisky, S. Lindgren, and J. C. Gottschal. 1995. Influence of $\mathrm{pH}$ and lactic acid concentration on Clostridium tyrobutyricum during continuous growth in a $\mathrm{pH}$-autostat. J. Appl. Bacteriol. 79:663-670.

Waes, G., A. v. Heddeghem, and A. Van Heddeghem. 1990. Prevention of butyric acid fermentation by bacterial centrifugation of the cheese milk. Bull. Int. Dairy Fed. 251:47-50.

Zwietering, M. H., J. C. d. Wit, and S. Notermans. 1996. Application of predictive microbiology to estimate the number of Bacillus cereus in pasteurised milk at the point of consumption. Int. J. Food Microbiol. 30:55-70. 